\title{
A LAICIDADE COMO OBJETO DE PRODUÇÃO INTELECTUAL
}

José Antonio Sepulveda ${ }^{\mathrm{i}}$

Resumo: Este texto tem por objetivo levantar e analisar a produção sobre Laicidade registrada no Observatório da Laicidade na Educação (OLÉ), em especial na sua página da internet no link chamado "biblioteca" na aba "textos disponíveis na internet". A proposta é contribuir na construção de uma bibliografia mais atualizada sobre o tema. O recorte temporal é de 2000 a 2018, todavia a maior parte dos textos selecionados na mencionada aba foi do período em que o OLÉ esteve ligado ao Núcleo de Políticas Públicas e Direitos Humanos da UFRJ, entre 2007 e 2013. Isso se justifica pelo fato de o Observatório, nesse momento, ter um mínimo de estrutura de funcionamento: bolsistas, funcionários e docentes. Os textos foram organizados em quatro grupos: Ensino Religioso nas escolas públicas; laicidade a partir de perspectivas históricas e filosóficas; a relação entre a laicidade, a política e a legislação; e, por último, a relação da laicidade com o ensino de ciências.

Palavras-chave: OLÉ; laicidade; educação.

\section{LAICITY AS AN INTELLECTUAL PRODUCTION OBJECT}

Abstract: This text aims to survey and analyze the production on Laicity registered in the Observatory of Laicity in Education (OLÉ), especially on its website at the link called "library" in the "texts available on the internet" tab. The proposal is to contribute to the construction of a more updated bibliography on the subject. The time frame is from 2000 to 2018, however most of the texts selected in the mentioned tab were from the period in which OLÉ was linked to the UFRJ Center for Public Policy and Human Rights, therefore, between 2007 and 2013.This is justified by the fact that the Observatory, at this moment, has a minimum of operating structure: scholarship holders, staff and teachers. The texts were organized into four groups: Religious Education in public schools; secularism from historical and philosophical perspectives; the relationship between secularism, politics and legislation; and lastly, the relationship of secularism with science teaching.

Keywords: OLÉ; secularity; education.

\section{Introdução}

Este texto tem por objetivo levantar e analisar a produção sobre Laicidade registrada no Observatório da Laicidade na Educação (OLÉ) ${ }^{1}$. O intuito é, a partir de uma base de dados, tentar mapear o que se produz sobre o tema. A opção pela base de dados do OLÉ se dá pelo fato de eu estar assumindo atualmente a coordenação do observatório. Portanto, essa opção é também uma forma de interagir com a produção desse órgão. 
O OLÉ, com a atual nomenclatura, é herdeiro do antigo Observatório da Laicidade do Estado. Um projeto do Professor Luiz Antonio Cunha e outros docentes, na sua maioria da Faculdade Educação da Universidade Federal do Rio de Janeiro (UFRJ), dentro do Núcleo de Estudos de Políticas Públicas e Direitos Humanos da instituição, o NEPP-DH, no período de 2007 a 2013. Funcionava como um Projeto de Extensão e se focou na elaboração e organização de uma página internet.

Após 2013, por seis anos, o OLÉ funcionou como uma rede independente de colaboradores até ser absorvida, em 2019, pela Faculdade de Educação da Universidade Federal Fluminense. Este texto é o primeiro esforço de reflexão dessa nova realidade. Assim, optei por fazer uma análise de um link específico da página intitulado "Biblioteca", na aba "Textos disponíveis na internet"2.

A maior parte dos textos selecionados na mencionada aba foi do tempo em que o OLÉ esteve ligado ao NEPP-DH/UFRJ, entre 2007 e 2013. Isso se justifica pelo fato de o Observatório, nesse período, ter um mínimo de estrutura de funcionamento, afinal ele estava institucionalizado com bolsistas, funcionários e docentes. No entanto, em 2014, com a aposentadoria do professor Luiz Antonio Cunha da UFRJ, o OLÉ perdeu seu caráter institucionalizado, o que impactou diretamente na manutenção da sua estrutura. Com essa mudança, o Observatório passou a depender de uma dedicação a mais de seus membros. Assim, os levantamentos ficaram mais imprecisos, o que prejudicou a pesquisa, que sofreu lacunas de produção, ou seja, algumas informações não puderam ser catalogadas pela instituição.

É importante ressaltar que já existe uma boa análise da produção sobre o tema laicidade, religião e educação, feita por Maria da Graça Setton e Gabriela Valente (2016). As autoras objetivaram com seus estudos mapear a produção existente sobre religião/educação nas revistas qualificadas na plataforma Scielo. A investigação teve como recorte temporal o período compreendido entre 2003 e 2013 . No que diz respeito às conclusões obtidas, as autoras apontam que o Brasil é um país fortemente religioso, ainda que as religiões tradicionais tenham perdido espaço. Ainda em suas palavras, a religiosidade do brasileiro apresenta-se forte enquanto prática de cultura, sendo a fé, para muitos, um alento para os momentos de vazios institucionais e existenciais, bem como instrumento identitário.

Dessa forma, o trabalho de Setton e Valente de 2016, intitulado "Religião e Educação no Brasil: uma leitura em periódicos (2003-2013)", dialoga com este trabalho, servindo de base para consulta. Vale ressaltar que o objetivo deste artigo não é comparar as bases de dados, mas sim dar visibilidade à plataforma do OLÉ que, conforme já mencionado, carece de dados.

Assim, mesmo com algumas dificuldades provocadas pelos limites da própria página, me dispus a fazer uma análise do que foi selecionado, tentando criar uma chave de interpretação que justifique a seleção do material feita pela equipe do OLÉ. Em princípio separei os artigos em quatro grandes grupos 
de análise. A ideia não era fazer uma tipologia, mas sim um exercício de reflexão sobre o que se produz acerca da laicidade no Brasil, pela perspectiva do Observatório.

Antes de tudo, vale afirmar que não estou propondo organizar nenhuma estrutura tipológica. A ideia aqui é investigar a base de dados como um processo de produção de conhecimento sobre o tema, evitando qualquer estruturação que impeça uma interpretação mais precisa do processo histórico mais amplo. Segundo Thompson (1981), “a estrutura, como uma baleia, abre suas mandíbulas e engole o processo: a partir de então o processo sobrevive de maneira infeliz na barriga da estrutura." (p.105). Assim, o que vale neste trabalho é o processo e a experiência adquirida.

Dessa forma, atuo com a perspectiva de experiência, ou seja, a partir de um movimento constante, construtor de sentidos que resultam do diálogo entre o ser social e a consciência social (THOMPSON, 1981). A análise dos dados faz parte desse processo de construção de conhecimento sobre a realidade, e no caso deste texto especificamente, sobre os dados referentes à produção de conhecimento social sobre laicidade. Como experiência, analisar a base de dados do OLÉ é resultado da construção de um diálogo entre o pesquisador e o conhecimento social acumulado pelo Observatório. Segundo Thompson (1981):

A experiência surge espontaneamente no ser social, mas não surge sem pensamento. Surge porque homens e mulheres (e não apenas filósofos) são racionais, e refletem sobre o que acontece a eles e ao seu mundo. Se tivermos de empregar a (difícil) noção de que o ser social determina a consciência social, como iremos supor que isso se dá? Certamente não iremos supor que o 'ser' está aqui, como materialidade grosseira da qual toda idealidade foi abstraída, e que a 'consciência' (como idealidade abstrata) está ali. Pois não podemos conceber nenhuma forma de ser social independentemente de seus conceitos e expectativas organizadores, nem poderia o ser social reproduzir-se por um único dia sem o pensamento. O que queremos dizer é que ocorrem mudanças no ser social que dão origem a experiência modificada; e essa experiência é determinante, no sentido de que exerce pressões sobre a consciência social existente, propõe novas questões e proporciona grande parte do material sobre o qual se desenvolvem os exercícios intelectuais mais elaborados." (p.16).

Pensando essa análise como a minha primeira experiência com a base de dados do novo OLÉ, é que inicio a minha reflexão. As quatro seções que se seguem foram divididas a partir de quatro grupos de análise, como já mencionado. O primeiro refere-se ao Ensino Religioso (ER) nas escolas públicas; o segundo é a construção da laicidade a partir de perspectivas históricas e filosóficas; o terceiro, a relação entre a laicidade, a política e a legislação e, por último, a relação da laicidade com o ensino de ciências.

\section{Ensino Religioso nas escolas públicas}

Esse grupo de análise possui 30 artigos com assuntos variados referentes ao Ensino Religioso nas escolas públicas. Destaco inicialmente o trabalho de Ana Maria Cavalieri, em especial nos artigos 
“Quando o Estado pede socorro à religião", publicado em 2006, e no artigo de 2007, "O mal-estar do ensino religioso nas escolas públicas". Em ambos a autora procura analisar o impacto do Ensino Religioso confessional ${ }^{3}$ nas escolas do Estado do Rio de Janeiro com base na lei 3.459/2000, demonstrando as disputas entre o campo educacional e o religioso, bem como as disputas internas do campo religioso 4 por uma espécie de "colonização" das escolas públicas do Estado.

No mesmo caminho dos artigos de Ana Maria Cavalieri, identificamos o de Boris Maia e Silva (2012), intitulado "Ensino Religioso e resistência moral: dilemas na implantação da lei 3459/00 no Rio de Janeiro". O trabalho analisa os impactos da regulamentação do Ensino Religioso confessional nas escolas públicas do Estado do Rio de Janeiro. Com objetivos e metodologias diferentes de Cavalieri, Maia e Silva procura entender a partir de um estudo etnográfico os impactos de tal legislação no cotidiano dos diferentes agentes escolares. Outro texto que também merece destaque no que concerne à análise do ER no Estado do Rio de Janeiro, é o artigo de Pinho e Vargas, de 2015, com o título "Ensino Religioso no Estado do Rio de Janeiro: conceitos, história e legislações”, o qual trata do ensino confessional a partir de uma análise histórica e legal do conceito de laicidade.

Da mesma forma destaco o artigo de Carlos Eduardo Oliva, "Entre a cruz e o plenário: os Projetos de Lei da Assembleia Legislativa do Estado do Rio de Janeiro em torno do Ensino Religioso nas escolas públicas fluminenses (1999-2007)”, de 2015, com uma análise apurada das legislações referentes ao ER no Estado do Rio de Janeiro.

Destaco ainda que um caminho bem comum dos artigos de análise do Ensino Religioso nas escolas públicas é a partir do debate curricular. Nesse sentido destaco os seguintes textos: “Análise dos Parâmetros Curriculares Nacionais para o Ensino Religioso nas escolas públicas”, de 2005, escrito por Toledo e Amaral; "Currículo e Diversidade Cultural: uma abordagem a partir do Ensino Religioso nas escolas públicas”, de 2011, com autoria de Alberes Siqueira Cavalcanti; "O Sistema Nacional de Educação e o Ensino Religioso nas escolas públicas", de 2013, e "A entronização do ensino religioso na Base Nacional Curricular Comum”, de 2016a, ambos de Luiz Antonio Cunha.

Existe também um conjunto considerável de artigos que tratam da questão da presença religiosa nas escolas para além da disciplina ER. É o caso do trabalho de Emerson Giumbelli, de 2008, "A presença do religioso no espaço público: modalidades no Brasil”; de Branco e Corsino, de 2015, "O discurso religioso em uma escola de Educação Infantil: entre o silenciamento e a discriminação"; os trabalhos solos de Jordanna Castelo Branco intitulados "O Amor de Jesus preenche todos os vazios: os discursos religiosos nas paredes de uma escola de educação infantil em Duque de Caxias (RJ)" e "Quem vai orar?!: Os discursos religiosos entre adultos e crianças em uma escola pública de educação infantil”, ambos de 2016. 
Boa parte da produção sobre ER incide em análises de casos específicos a partir de estudos das redes municipais de ensino. Destaco primeiramente o trabalho de 2007 de Janaina Alencar Lui, intitulado "Entre crentes e pagãos: Ensino Religioso em São Paulo", uma boa análise sobre o ER em São Paulo. Destaco ainda o conjunto de artigos produzidos em 2012 no Dossiê organizado por Roseli Fischmann para a revista Notandum, cujos trabalhos se dedicavam a analisar conjunturas específicas do ER em alguns municípios do Brasil, a maioria do Rio de Janeiro. São autores desse dossiê: Vânia Claudia Fernandes, com um trabalho sobre Duque de Caxias (RJ); Leonardo Barros Medeiros sobre Petrópolis (RJ); Leila Gasperazzo Ignatius Grassi sobre São José dos Campos (SP); Thiago dos Santos Molina sobre Salvador (BA); Fernando Seffner e Renan Bulsing dos Santos sobre três municípios do Rio Grande do Sul (Alvorada, São Leopoldo e Porto Alegre), Jacira Helena do Valle Pereira e Miriam Mity Nishimoto sobre o Estado do Mato Grosso do Sul e Luiz Antonio Cunha fazendo uma comparação entre Duque de Caxias e Petrópolis, no Estado do Rio de Janeiro. Por último, ressalto o artigo de Jordanna Castelo Branco de 2017, intitulado "Trama na Cinelândia: a normatização do Ensino Religioso no município do Rio de Janeiro", analisando a implementação da Lei 5.303/11 que cria o quadro permanente de professores de ER no município do Rio de Janeiro.

Ainda com relação ao ER nas escolas públicas, mais dois caminhos se destacam. O primeiro refere-se à questão identitária. Muitos artigos preocupados com a relação entre religião e preconceito visualizam a laicidade como uma arma contra a intolerância de qualquer natureza. É o caso do artigo de Nilton Rodrigues Junior, de 2014, “A presença da religião na educação popular: o caso do pré-vestibular para negros e carentes"; do artigo de Sepulveda e Sepulveda (2016a), "O pensamento conservador e sua relação com práticas discriminatórias na educação: a importância da laicidade"; de Aurenéa Maria de Oliveira, "Diferença sexual e religiosa no currículo de Ensino Religioso em escolas de Recife"; de Rocha, Rocha e Lima, "Intolerância religiosa em escolas públicas no Rio de Janeiro"; de Russo e Almeida, "Yalorixás e educação: discutindo o ensino religioso nas escolas", todos de 2016.

O segundo caminho e último grupo de análise da seção, refere-se aqueles artigos que defendem o ER nas escolas públicas. Esse é o caso do artigo de Maria Judith Sucupira da Costa Lins intitulado "Ensino Religioso no desenvolvimento integral da pessoa", de 2006. Tal autora defende a necessidade de a escola dar uma formação religiosa para seus alunos como forma de respeito às religiões. Outros artigos caminham na defesa de um ER interconfessional e ecumênico como sendo laico. É o caso do artigo de Marília de Franceschi Neto Domingos, "Ensino Religioso e Estado Laico: uma lição de tolerância", de 2009. Outro artigo na mesma direção é de autoria de Clera Cunha e Claudia Borbosa, de 2011, "O ensino religioso na escola pública e suas implicações em desenvolver o senso de respeito e tolerância dos alunos em relação aos outros e a si próprios”. Para finalizar o artigo, de Emerson Giumbelli, também de 2011 , 
"Ensino religioso e assistência religiosa no Rio Grande do Sul”, que traça um panorama da questão religiosa a partir dos problemas referentes ao ER nas escolas públicas e na Assistência Social, lugares historicamente controlados pela religião. Nesse artigo, especificamente, não fica clara a posição do autor sobre a disciplina ER, entretanto ele a toma como uma realidade dada.

\section{Laicidade perspectiva histórica e filosófica}

Essa seção tem por objetivo demonstrar como o OLÉ privilegia as análises a partir de perspectivas históricas e filosóficas. Existe uma preocupação evidente com questões conceituais e isso se reflete nos 25 artigos selecionados. É importante ressaltar que muitos dos artigos até aqui analisados apresentam em determinadas partes algum caráter histórico ou filosófico, entretanto, não são esses os seus objetivos.

Para abrir essa seção destaco os artigos que procuram fazer uma análise histórica do período imperial até a $1^{a}$ República. Irma Rizzini escreveu "O imaginário divino e o amor da pátria: tensões entre a igreja e a instrução pública nas províncias amazônicas", em 2006, sobre a educação no Amazonas do século XIX. Luiz Antonio Cunha escreveu um importante livro, disponibilizado na íntegra na página do OLÉ: “A educação brasileira na primeira onda laica: do Império à República”, de 2017. Maria Zélia Borba Rocha escreveu em 2013 “A luta político-cultural pelo ensino religioso no Brasil”, um estudo que focaliza também a partir do século XIX.

Alguns artigos procuram analisar o processo histórico da laicidade em uma longa duração, buscando as permanências e rupturas. É o caso do texto de Ana Maria Gonçalves e Tamiris Alves Muniz, intitulado "A permanência da disciplina Ensino Religioso no currículo escolar brasileiro", publicado em 2014; do artigo de Luiz Antônio Cunha de, 2007, "Sintonia oscilante: Religião, Moral e Civismo no Brasil - 1931/1997 e "Autonomização do campo educacional: efeitos do e no ensino religioso", de 2006; do artigo de Sepulveda e Sepulveda, de 2017, “A disciplina Ensino Religioso: história, legislação e práticas"; e, para finalizar, de José Vaidergorn, de 2008, "Ensino Religioso, uma herança do autoritarismo".

Alguns artigos focaram em algum período específico da história da educação brasileira. $\mathrm{O}$ artigo de Rosângela Veiga Júlio Ferreira e Jeniffer de Souza Faria focam nos anos de 1930 e no trabalho da Cecília Meireles, "A laicidade no discurso jornalístico de Cecília Meireles: imagens da década de 1930", publicado em 2011. Marilândes Mól Ribeiro de Melo, Ione Ribeiro Valle e Rafaela Azevedo de Souza publicaram em 2016 o artigo "Entre a religião e o secularismo: incursão nas memórias do professorado catarinense dos anos 1960". E, por fim, o artigo intitulado "Um acordo insólito: Ensino Religioso sem ônus para os poderes públicos na primeira LDB”, de Luiz Antonio Cunha e Vânia Claudia Fernandes, de 
2012, e, encerrando, de Luiz Antonio Cunha "Educação laica na Constituinte: uma avaliação retrospectiva", de 2018

Outro caminho bem visível desse grupo é o de análise filosófica. Duas linhas de análise saem daqui. A primeira diz respeito aos artigos que discutem elementos filosóficos ligados ao Ensino Religioso nas escolas públicas, a saber: “A luta pela ética no ensino fundamental: religiosa ou laica?”, de Luiz Antonio Cunha, publicado em 2009; “O ensino laico e a formação filosófica”, de Adriana Mattar Maamari, 2014; "O dilema epistemológico do Ensino Religioso", de Evaldo LuisPauly, 2004. Dois artigos de Cesar A. Ranquetat Jr. completam essa série: "Laicidade, Laicismo e Secularização: definindo e esclarecendo conceitos", de 2008, e "Religião em sala de aula: o Ensino Religioso nas escolas públicas brasileiras", de 2007. Seguindo a mesma linha, mas com uma análise mais voltada para a Bioética, está o trabalho de Renato José de Oliveira, de 2013, “A Bioética na Educação Escolar: uma discussão importante".

A segunda linha analisa o debate interno do campo religioso e seus reflexos na educação e na sociedade. Nela, encontram-se os três artigos de Ricardo Mariano: "Efeitos da secularização do Estado, do pluralismo e do mercado religiosos sobre as igrejas pentecostais", de 2007; "Expansão e ativismo político de grupos evangélicos conservadores: secularização e pluralismo em debate", de 2016; e, por último, "Laicidade à brasileira: católicos, pentecostais e laicos em disputa na esfera pública", de 2011.

Para finalizar essa seção, destaco três trabalhos que têm por característica trabalhar o diálogo entre laicidade, religião, história e filosofia. Ressalto primeiro o trabalho de Paula Leonardi no projeto Pensar a Educação em Revista, intitulado "Educação e Catolicismo", de 2016; o texto de Luiz Antônio Cunha no Visioni Latino Americaneè la revista del Centro Studi per l'America Latina, intitulado "Confessionalismo versus laicidade na educação brasileira: ontem e hoje", de 2012; e , por último, a resenha de Patrizia Piozzi, de 2009, "Ensino laico e democracia na época das luzes: as 'memórias' de Condorcet para a instrução pública", sobre o debate da laicidade e da democracia no Iluminismo, tendo como foco a obra de Condorcet então publicada: "Cinco memórias sobre a instrução pública”.

\section{Laicidade, legislação e política}

A discussão sobre a legislação e política é muito forte também dentro dos artigos da base de dados do OLÉ. Consegui mapear 23 artigos. A ênfase desse grupo é discutir as relações que se estabelecem entre os agentes políticos referentes ao debate sobre religiões e o ER nas escolas, tendo como foco principal um contexto mais amplo. Um exemplo claro desse grupo é o texto do Luiz Antonio Cunha, de 2016b, chamado "O projeto reacionário de educação", no qual a questão da laicidade está sendo discutida 
em debate maior abrangendo o reacionarismo presente hoje na educação brasileira. É o mesmo caso do texto de Fernando Penna "Programa 'Escola sem Partido"5: uma ameaça à educação emancipadora", de 2016.

Os textos acima mencionados têm em comum a defesa da democracia. Vemos a ideia da laicidade como um dos pilares fundamentais da democracia em uma lógica cidadã também desenvolvida no texto de Sepulveda, Sepulveda e Fernandes, de 2015, intitulado "Ensino Religioso e laicidade: suas implicações para a implementação da democracia nas escolas" e no artigo de Cristián Parker, de 2008, com o título "Pluralismo religioso, educación y ciudadanía" . Vale destacar ainda o artigo de Luiz Antonio Cunha sobre as forças políticas que atuam dentro do Congresso Nacional na disputa pelo controle do ER durante a tramitação da atual Lei de Diretrizes e Bases (LDB), "Hegemonia e confronto na produção da segunda LDB: o ensino religioso nas escolas públicas”, publicado em 2014.

Pensando a laicidade a partir de uma pesquisa comparativa entre países, destacamos os artigos de Ari Pedro Oro, em coautoria com Marcela Ureta, de 2007, os quais discorrem sobre os países da América Latina: "Religião e política na América Latina: uma análise da legislação dos países”, e "A laicidade no Brasil e no Ocidente: algumas considerações”, de 2011, comparando a laicidade em vários países do Ocidente; e, por último, o artigo de Luiz Antonio Cunha, de 2006, intitulado "Ensino Religioso nas escolas públicas: a propósito de um seminário internacional”.

Os artigos mais enfáticos dessa seção são os que se referem ao debate legal da laicidade, ou seja, à implementação de projetos de lei, à constitucionalidade da laicidade e às consultas ao supremo. Esse conjunto de artigos destaca ainda a reação política de diferentes grupos religiosos frente à laicidade, é o caso, por exemplo, do artigo de Ricardo Mariano, de 2006, intitulado “A reação dos evangélicos ao novo Código Civil". Dentro do campo jurídico tem-se o artigo de Isso Chaitz Scherkerkewitz, de 2002, “O direito de religião no Brasil"6; de Letícia de Campos Velho Martel, de 2007, "Laico, mas nem tanto: cinco tópicos sobre liberdade religiosa e laicidade estatal na jurisdição constitucional brasileira"; dois artigos de Roseli Fischmann, respectivamente de 2011 e 2012, "Educación laica (em escuelas públicas): una cuestión política, cultural y de derecho" e "Inconstitucional: o ensino religioso em escolas públicas em questão".

Sobre a Concordata Brasil e Santa Sé destaco os seguintes artigos: "Secularização e laicidade do Estado brasileiro depois da Constituição de 1988”, de Águeda Bernadete Bittencourt e Vinicius Parolin Wohnrath, de 2013; “A educação na Concordata Brasil-Vaticano”, de Luiz Antonio Cunha, de 2009; "A proposta de Concordata com a Santa Sé e o debate na Câmara Federal”, de Roseli Fischmann, também de 2009”. 
Para fechar essa seção, menciono o destaque que a base de dados do OLÉ dá aos relatórios de trabalho sobre laicidade elaborados por diferentes instituições, a saber: o Relatório da Relatoria de Direitos Humanos e Estado Laico da Plataforma de Direitos Humanos - Dhesca-Brasil, escrito por Ivanilda Figueiredo em 20167; a produção do Instituto de Estudos da Religião (ISER) denominada "Religiões em conexão: números, direitos e pessoas", com textos organizados por Christina Vital da Cunha e Renata de Castro Menezes em 2014; a reunião ampliada do ISER de 2015 em parceria com o Movimento Estratégico Estado Laico (MEEL), com o título de "Fundamentalismo Religioso e Estado Laico"; também em 2015 o seminário da MEEL intitulado "Laicismo ou Laicidade: desafios atuais do Estado Brasileiro"9; e, por último, o livro produzido pela Sociedade Brasileira para o Progresso da Ciência (SBPC), na comemoração de seus 70 anos, organizado por Claudia Masini d'Avila-Levy e Luiz Antônio Cunha, com o título de "Embates em torno do Estado Laico", de 2018. Partimos agora para a última seção.

\section{Laicidade e ensino de ciências}

Essa é a menor seção de todas com apenas seis artigos que se destacam pelo foco específico nos problemas referentes à laicidade e o ensino de Ciências, mais precisamente os problemas do embate entre religião e ciência. Temas como origem da vida, evolucionismo e outros que apontam tensões com os dogmas religiosos possuem particularidades que serão tratadas nos artigos abaixo.

O primeiro texto que destaco, por ordem cronológica, é "Os sentidos de natureza na formação e na prática científica", de Eliane Brígida Morais Falcão e Flavio Silva Faria de 2008. Nele, os autores discutem a forma como a sociedade em geral, inclusive a científica, entende o conceito de natureza. $\mathrm{O}$ artigo enfatiza a presença das concepções religiosas de mundo na interpretação do conceito, revelando a existência de uma lacuna na formação científica superior: a carência de uma formação epistemológica mais aprofundada.

O segundo artigo é de 2008, de Roseli Fischmann, intitulado "Ciência, tolerância e Estado laico". Nesse artigo, a autora aponta o conjunto de tensões que existem entre religião e ciência. Ela entende que há diversas trilhas de análise possíveis para se compreender a relação entre a ciência e o Estado laico. A mais convencional delas, refere-se à relação histórica entre as instituições religiosas e o fazer científico, mais especificamente à relação entre a Igreja Católica Apostólica Romana e a ciência.

Trazemos ainda outro texto de Eliane Brígida Morais Falcão, mas dessa vez em parceria com Paulo Roberto de Araújo Porto, de 2010. Nele, os autores discutem as tensões vivenciadas pelos os professores de Ciências ao ensinar sobre a origem da vida e o evolucionismo. O artigo em questão chama- 
se "Teorias da origem e evolução da vida: dilemas e desafios no ensino médio". Esse texto se destaca também em função do segmento abordado, o ensino médio, pela escassa literatura existente sobre essa população discente.

O artigo de 2016 "Criacionismo: transformações históricas e implicações para o ensino de Ciências e Biologia”, dos autores Luís Fernando Marques Dorvillé e Sandra Lúcia Escovedo Selles”, enfrenta a tensão entre o criacionismo e o evolucionismo. Os autores sugerem que o enfrentamento dessa situação precisa envolver práticas que estimulem uma melhor compreensão da atividade científica, enfatizando a relevância da sua abordagem na formação inicial. Eles destacam ainda a importância de atividades didáticas que promovam um espaço de respeito pelas diferentes visões de mundo ao mesmo tempo em que trabalhem o conhecimento transmitido pela ótica do estranhamento, desabilitando zonas de conforto.

Para terminar essa seção faço um destaque em separado para a publicação do Observatório de Sexualidade e Política, de julho de $2008^{10}$, no contexto da visita do papa ao Brasil. Nessa publicação existe uma importante reflexão sobre a tensão ciência e religião a partir da análise de células-tronco e das tecnologias reprodutivas, as chamadas "heresias" da Ciência segundo a Igreja. Há também uma boa discussão sobre laicidade, tendo como foco as pressões que a sociedade científica recebeu por conta da visita do Pontífice da Igreja Católica Apostólica Romana.

Dessa forma, encerro essa seção com um quadro geral das publicações feitas pelo OLÉ, disponíveis no link "Biblioteca" na aba "Textos".

\begin{tabular}{|l|l|l|}
\hline Grupos & Quantidade de artigos & $\%$ \\
\hline $\begin{array}{l}\text { Ensino Religioso nas escolas } \\
\text { públicas }\end{array}$ & 30 & 35,7 \\
\hline $\begin{array}{l}\text { Laicidade perspectiva } \\
\text { histórica e filosófica }\end{array}$ & 25 & 29,7 \\
\hline $\begin{array}{l}\text { Laicidade, legislação e } \\
\text { política }\end{array}$ & 23 & 27,3 \\
\hline $\begin{array}{l}\text { Laicidade e ensino de } \\
\text { ciências }\end{array}$ & 6 & 7,3 \\
\hline Total & 84 & 100 \\
\hline
\end{tabular}

Fonte: produção própria.

Após tudo o que foi dito e analisado até o momento, é válido ressaltar a importância de se fazer estudos sobre a produção de artigos acerca da laicidade, principalmente na atualidade brasileira e do mundo, face ao momento de ataque à democracia. 


\section{Considerações finais}

Entender a construção da base de dados do OLÉ como uma experiência me possibilitou compreender essas informações como um processo de construção de um instrumento intelectual de extrema importância para o debate da laicidade na educação. Isso me inspirou algumas análises, das quais duas se mostraram centrais para tentar entender a produção sobre a laicidade, bem como o conteúdo armazenado na base de dados do OLÉ. Tomando por referência a tabela apresentada, primeiro ressalto o equilíbrio da seleção dos 84 artigos disponibilizados na página do Observatório. O Grupo Ensino religioso nas escolas públicas teve o maior número de artigos, 30, o que representa 35,7\% dos textos. O grupo Laicidade perspectiva histórica e filosófica teve 25 artigos, representando 29,7\% dos textos. Em seguida, o grupo Laicidade Legislação e Política somou 23 artigos, representando 27,3\% dos textos e, por último, o grupo Laicidade e Ensino de Ciências produziu seis artigos, representando 7,3\%. Assim, excetuando esse último grupo, o equilíbrio é uma marca dessa seleção, o que indica que as pessoas seguiram uma determinada orientação. Apesar dessa diretriz não se evidenciar no sitio, os números sinalizam isso. A menor produção quantitativa do último grupo, seis artigos, se justifica pela própria composição do OLÉ, que possui no seu corpo de colaboradores somente alguns professores da área de Ciências. Como a maioria advém das Ciências Humanas, as questões de ordem histórica, sociológica, filosófica e pedagógica dos artigos ganharam mais força.

A segunda conclusão que se pode fazer, inclusive em comparação com o trabalho de Setton e Valente (2016), é o crescimento dos artigos sobre a temática a partir de 2010. Levanto dois indícios para tentar entender esse aumento. O primeiro tem relação com a assinatura da Concordata entre o Brasil e a Santa Sé, que, entre outras coisas, reforça o compromisso do Estado brasileiro com o ER nas escolas públicas. O segundo tem a ver com o aumento do fundamentalismo religioso na sociedade brasileira nos últimos anos. As disputas no campo religioso em momentos de crise econômica são fundamentais para conquista de fiéis. Portanto, a elaboração de um discurso conservador religioso como base na construção do medo na sociedade reforça essa análise. Esse tipo de estruturação se dá a partir da invenção de supostos inimigos, chamados de doutrinadores, dos quais o mais poderoso denomina-se "ideólogo de gênero". Essa argumentação se fundamenta na falsa premissa de que nas escolas públicas de educação básica os professores estão ensinando às crianças que elas podem ter o gênero e orientação sexual que quiserem, podendo "escolher" o que querem ser.

Por fim, vale ressaltar a importância de se estimular a produção de artigos relacionados à tensão entre religião e Ensino de Ciências. Essa temática é extremamente importante para se construir argumentos mais eficientes para fortalecer a laicidade e a democracia no Brasil, e que, como vimos neste texto, ainda se apresenta de forma incipiente. Com certeza, existe muito mais produção sobre essa 
temática do que a que se apresenta catalogada na página do OLÉ, e, exatamente por isso, mais artigos sobre a relação laicidade e ensino de ciências seriam muito bem-vindos.

\section{Referências bibliográficas}

BITTENCOURT, Agueda Bernadete; WOHNRATH, Vinicius Parolin. Secularização e laicidade do estado brasileiro depois da constituição de 1988.Revista Brasileira de Política e Administração da Educação, vol. 29, no. 2, maio/agosto 2013.

BRANCO, Jordanna Castelo. Trama na Cinelândia: a normatização do Ensino Religioso no município do Rio de Janeiro. Revista FAEEBA, v. 26, n. 48, p. 243-256, jan./abr. 2017.

. Quem vai orar? Os discursos religiosos entre adultos e crianças em uma escola pública de educação infantil. Horizontes, v. 34, p. 81-90, 2016.

. O amor de jesus preenche todos os vazios: os discursos religiosos nas paredes de uma escola de educação infantil em Duque de Caxias (RJ). Educação em Foco, v. 21, p. 345-363, 2016.

; CORSINO, Patrícia. O discurso religioso em uma escola de educação infantil: entre o silenciamento e a discriminação. Revista Eletrônica de Educação, v. 9, n. 3, 2015.

CAVALCANTI, Alberes de Siqueira. Currículo e diversidade cultural: uma abordagem a partir do ensino religioso nas escolas públicas. Revista Fundamento, v. 1, n. 3, mai/ago 2011.

CAVAliERE, Ana Maria. Quando o Estado pede socorro a Religião. Revista Contemporânea de Educação, v.1. n.2, p. 1-12, jul./dez. 2006.

O mal-estar do ensino religioso nas escolas públicas. Cadernos de Pesquisa, v. 37, n. 131, p. 303-332, maio/ago. 2007.

CORSINO, Patricia; BRANCO, Jordanna Castelo. Obrigatoriedade escolar aos quatro anos: indagações sobre materiais didáticos escolares. Textura, v. 18, p. 125-149, 2016.

CONDORCET, Marquis de. Cinco memórias sobre a instrução pública. São Paulo. Editora da UNESP. 2008. Resenha de: PIOZZI, Patrizia. Ensino laico e democracia na época das luzes: as 'memórias' de Condorcet para a instrução pública. Educação e Sociedade, v. 30, n. 108, out. 2009.

CUNHA, Luiz Antonio. Ensino religioso nas escolas públicas: a propósito de um seminário internacional. Educação e Sociedade, v. 27, n. 97, set./dez. 2006.

Autonomização do campo educacional: efeitos do e no ensino religioso. Revista contemporânea de educação, n. 2, 2006.

. Sintonia oscilante: religião, moral e civismo no Brasil - 1931/1997. Cadernos de Pesquisa, v. 37, n. 131, maio/ago. 2007.

A educação na concordata Brasil-Vaticano. Educação e Sociedade, v. 30, n. 106, abr./jun. 2009. 
- A luta pela ética no ensino fundamental: religiosa ou laica?. Cadernos de Pesquisa, n. 137, maio/agosto 2009.

- Confessionalismo versus laicidade na educação brasileira: ontem e hoje. Visione LatinoAmericane, ano III, n. 4, janeiro 2011.

O Sistema Nacional de Educação e o ensino religioso nas escolas públicas. Educação $e$ Sociedade, v. 34, n. 124, jul./set. 2013.

Hegemonia e confronto na segunda LDB: o ensino religioso nas escolas públicas. ProPosições, v. 25, n. 1, janeiro/abril 2014.

A Entronização do Ensino Religioso na Base Nacional Curricular Comum. Educação e Sociedade, v. 37, nº 134, p.266-284, jan.-mar., 2016 a.

O projeto reacionário de educação. Rio de Janeiro: Edição do Autor, $2016 \mathrm{~b}$.

- A Educação Brasileira na Primeira Onda Laica: do Império à República. Rio de Janeiro: Edição do Autor, 2017.

Educação laica na Constituinte: uma avaliação retrospectiva. Retratos da Escola, v. 12, n. 24, 2018.

CUNHA, Luiz Antonio; FERNANDES, Vania. Um acordo insólito: ensino religioso sem ônus para os poderes públicos na primeira LDB. Educação e Pesquisa, v. 38, n. 4, 2012.

CUNHA, Clara B.; BARBOSA, Cláudia. O ensino religioso na escola pública e suas implicações em desenvolver o senso de respeito e tolerância dos alunos em relação aos outros e a si próprios. Revista Sacrilegens, v. 8, no. 1, dez 2011.

D’AVILA-LEVY, Claudia Masini; CUNHA, Luiz Antônio (Orgs.). Embates em torno do Estado laico. São Paulo: SBPC, 2018.

DOMINGOS, Marília De Franceschi Neto. Ensino Religioso e Estado Laico: uma lição de tolerância. Revista de Estudos da Religião, setembro, 2009.

DORVILLÉ, L. F. M; SELLES, S. L. E. Criacionismo: transformações históricas e implicações para o ensino de ciências e biologia. Cadernos de Pesquisa, v. 46, n. 160, p. 442-465, abr./jun. 2016.

FALCÃO, Eliane Brígida Morais; FARIA, Flávio Silva. Os sentidos de natureza na formação e na prática científica. Educação e Pesquisa, v. 33, n. 2, mai./ago., 2007.

; SANTOS, Alessandra Guida dos; LUIZ, Ronir Raggio. Conhecendo o mundo social dos estudantes: encontrando a ciência e a religião. Revista Electrónica de Enseñanza de Las Ciencias, v. 7, no. 2, 2008.

; PORTO, Paulo Roberto de Araújo. Teorias da origem e evolução da vida: dilemas e desafios no ensino médio. Revista Ensaio, v. 12, n. 3, set/dez 2010. 
FERREIRA, Rosângela Veiga Júlio; FARIA, Jeniffer de Souza. A laicidade no discurso jornalístico de Cecília Meireles: imagens da década de 1930. Sacrilegens, v. 8, n. 1, dez/2011.

FISCHMANN, R. Ciência, tolerância e Estado laico. Ciência e Cultura, v. 60, número especial, p. 42-50, jul. 2008.

A proposta de concordata com a Santa Sé e o debate na Câmara Federal. Educação e Sociedade, v. 30, n. 107, maio/ago. 2009.

. Educación laica (EnEscuelas Públicas): Una Cuestión Política, Cultural y de Derecho. Revista Internacional D'humanitats, jul-set, 2011.

. Ensino Religioso em Escolas Públicas: ameaças ao estado laico. Notandum, No 28, Jan/Abr, 2012.

. Estado laico, educação, tolerância e cidadania - para uma análise da Concordata Brasil Santa Sé. São Paulo: CEMOROC/EDF-FEUSP/FACTASH Editora, 2013.

GIUMBELLI, Emerson. O "baixo espiritismo" e a história dos cultos mediúnicos. Horizontes Antropológicos, Porto Alegre, ano 9, n. 19, 2003.

n. 2, 2008 .

A presença do religioso no espaço público: modalidades no Brasil. Religião e Sociedade, v. 28,

A religião nos limites da simples educação: notas sobre livros didáticos e orientações curriculares de ensino religioso. Revista de Antropologia, v. 53, n. 1, p. 39-78, 2010.

Ensino Religioso e assistência religiosa no Rio Grande do Sul: quadros exploratórios, civitas. Revista de Ciências Sociais, vol. 11, no. 2, maio/agosto 2011a.

A noção de crença e suas implicações para a modernidade: um diálogo imaginado entre Bruno Latour e TalalAsad. Horizontes Antropológicos, ano 17, n. 35, jan./jun. 2011.

GONÇALVES, Ana Maria; MUNIZ, Tamiris Alves. A permanência da disciplna Ensino Religioso no currículo escolar brasileiro. Teias, v.14, n. 39, 2014.

LEONARDI, Paula. Educação e catolicismo. Pensar Educação em Revista, v. 2, n. 4, p. 3-23, out$\operatorname{dez} / 2016$.

LINS, Maria Judith Sucupira da Costa. Ensino Religioso no desenvolvimento integral da pessoa. Revista Contemporânea de Educação, Rio de Janeiro, v. 1, n. 2, 2006.

LUI, Janayna de Alencar. Entre Crentes e Pagãos: Ensino Religioso em São Paulo. Cadernos de Pesquisa, v. 37, n. 131, p. 333-349, maio/ago. 2007.

MAAMARI, Adriana Mattar. O Ensino Laico E A Formação Filosófica. Revista Eletrônica de Educação, v. 8, n. 3, 2014.

MAIA E SILVA, Bóris. Ensino Religioso e resistência moral: dilemas na implantação da lei 3459/00 no Rio de Janeiro. Revista Ética e Filosofia Política, v. 1,nº 15, maio de 2012. 
MARIANO, Ricardo. A reação dos evangélicos ao novo código civil. Civitas. Revista de Ciências Sociais, FFCH/PUC-RS, Porto Alegre, v. 5, n. 2, 2006.

Efeitos da secularização do Estado, do pluralismo e do mercado religiosos sobre as igrejas pentecostais. Civitas - Revista de Ciências Sociais, FFCH/PUC-RS, Porto Alegre, v. 3, n. 1, 2007.

. Laicidade à brasileira: católicos, pentecostais e laicos em disputa na esfera pública. Civitas Revista de Ciências Sociais, Porto Alegre, v. 11, n. 2, maio/ago. 2011.

MARTEL, Letícia Campos Velho. Laico, mas nem tanto: cinco tópicos sobre liberdade religiosa e laicidade estatal na legislação constitucional brasileira. Revista Jurídica, v. 9, n. 86, ago./out 2007.

MELO, Marilândes Mól Ribeiro de; VALLE, Ione Ribeiro; SOUZA, Rafaela Azevedo de. Entre a religião e o secularismo: incursão nas memórias do professorado catarinense dos anos 1960. Revista Pedagógica, v.18, n.38, Maio/Ago. 2016.

OLIVA, Carlos Eduardo. Entre a cruz e o plenário: os Projetos de Lei da Assembleia Legislativa do Estado do Rio De Janeiro em torno do ensino religioso nas escolas públicas fluminenses (1999-2007). Anais da XV Jornada do PPGSA/UFRJ, Rio de Janeiro, 2015.

OLIVEIRA, Aurenéa Maria de. Diferença sexual e religiosa no currículo de ensino religioso em escolas de Recife. Revista Eletrônica de Educação, v. 10, n. 1, p. 128-142, 2016.

OLIVEIRA, Heli Sabino de. Laicidade e Religiosidade em escolas públicas de BH. Anais do VIII Seminário Nacional de Estudos e Pesquisa, UNICAMP, Campinas, 2009.

OLIVEIRA, Renato José de. A bioética na educação escolar: uma discussão importante. Educação Unisinos, V. 17, N. 1, 2013.

ORO, Ari Pedro. A Laicidade no Brasil e no ocidente. Civitas, v. 11, n. 2, p. 221-237, mai-ago, 2011.

; URETA, Marcela. Religião e política na América Latina: uma análise da legislação dos países. Horizontes Antropológicos, v. 13, n. 27, jan./jun. 2007.

PARKER, G. Cristian. Pluralismo religioso, educación y ciudadanía. Sociedade e Estado, n. 2, v. 23, 2008.

PAULY, Evaldo Luis. O dilema epistemológico do Ensino Religioso. Revista Brasileirade Educação, n.27, Set/Dez 2004.

PENNA, Fernando. Programa Escola sem Partido: uma ameaça à educação emancipadora. IN: GABRIEL, Carmen et. Alii. Narrativas do Rio de Janeiro nas aulas de História. Rio de Janeiro: Mauad, 2016.

PINHO, Leandro Garcia; VARGAS, Evandro Francisco Marques. Ensino Religioso no Estado do Rio de Janeiro: conceitos, história e legislações. Educ. temat. digit., SP v.17 n. 2 p.308-327 Maio/ago. 2015.

PIOZZI, Patrizia. Ensino laico e democracia na época das luzes: as "memórias" de condorcet para a instrução pública. Educação e Sociedade, vol. 30, n. 108, p. 917-922, out. 2009. 
RANQUETAT JR., C. A. Laicidade, laicismo e secularização: definindo e esclarecendo conceitos. Revista Tempo da Ciência, Santa Maria, v. 15, n. 30, $2^{\circ}$ semestre 2008.

; CÉSAR, A. Religião em sala de aula: O Ensino Religioso nas escolas públicas brasileiras. Revista Eletrônica de Ciências Sociais, ano i, ed. 1, fev, 2007.

RIZZINI, Irma. O imaginário divino e o amor da Pátria: tensões entre a igreja e a instrução pública nas províncias Amazônicas. Revista Contemporânea de Educação, v. 1, n. 2, 2006.

ROCHA, Marcos Porto; ROCHA, Jose Geraldo da; LIMA, Jacqueline Pinheiro. Intolerância religiosa em escolas públicas no Rio de Janeiro. Educação, v. 41, n. 3, p. 709-718, set./dez. 2016.

ROCHA, Maria Zélia Borba. A luta político-cultural pelo Ensino Religioso no Brasil, Revista Brasileira de História da Educação, v. 13.n. 2, maio/agosto 2013.

RODRIGUES JUNIOR, Nilton. A presença da religião na educação popular: o caso do pré-vestibular para negros e carentes. Revista Contemporânea de Educação, n. 17, jan/jun 2014.

SEPULVEDA, Denize. A religião e a homofobia no cotidiano escolar: a importância da laicidade para garantir os direitos das alunas e alunos homossexuais. Revista nuestramérica. v 4, n 8, 2016.

SEPULVEDA, Jose Antonio; SEPULVEDA, Denize. O pensamento conservador e sua relação com práticas discriminatórias na educação: a importância da laicidade. Teias, v. 17, v. 17, n. 47 out.-dez., 2016 .

;___ Conservadorismo e educação escolar. Movimento, ano 3, n 5, $2016 \mathrm{~b}$.

SEPULVEDA, Denize; SEPULVEDA, José Antônio. A disciplina Ensino Religioso: história, legislação e práticas. Educação, v. 42, N.1, jan-abr 2017.

; FERNANDES, Vânia Claudia. Ensino Religioso e laicidade: suas implicações para a implementação da democracia nas escolas. Revista Contemporânea de Educação, vol. 10, n. 19, jan/jun 2015.

SETTON, Maria da Graça J.; VALENTE, Gabriela. Religião e educação no Brasil: uma leitura em periódicos (2003-2013). Cadernos de Pesquisa, v. 46, p. 410-440, 2016.

SILVA, Allan do Carmo. Laicidade ou confessionalismo na escola pública: Naturalização da religião no ensino em Nova Iguaçu (RJ). Anais do XVI Endipe, 2012.

TOLEDO, Cézar de Alencar Arnaut de; AMARAL, Tânia Conceição Iglésias do. Análise dos Parâmetros Curriculares Nacionais para o Ensino Religioso nas escolas públicas, Revista Linhas, v. 6, n. 1, 2005.

VAIDEGORN, José. Ensino Religioso: uma herança do autoritarismo. Cadernos CEDES, v. 28, n. 76, set./dez., 2008.

VALENÇA, Cristina; FALCÃO, Eliane Barroso. Teoria da evolução: representações de professores pesquisadores de biologia e suas relações com o ensino médio. Revista Electrónica de Enseñanza de las Ciencias, v. 11, n. 2, p. 471-486, 2012. 
VARGAS, Evandro Francisco Marques; PINHO, L. G.O processo da escolarização do Ensino Religioso confessional no sistema público estadual do Rio de Janeiro: contrapontos da lei 3.459/00 à realidade escolar. Licencia \& Acturas, v. 4, p. 23-32, 2016.

\section{Notas:}

\footnotetext{
' Professor do Programa de Pós-Graduação em Educação da Universidade Federal Fluminense. Professor Adjunto IV da Faculdade de Educação da Universidade Federal Fluminense. Doutor em Educação pela Universidade Federal do Rio de Janeiro (2010). Líder do Diretório e do Grupo de Estudos e Pesquisa: Os Impactos do Conservadorismo na Educação Brasileira da UFF. Sub-líder do Grupo de Pesquisa Gêneros, Sexualidaes e Diferenças nos Vários EspaçosTempos Cotidianos (GESDI) da UERJ/FFP. Coordenador do Observatório da Laicidade na Educação (OLÉ).

1 www.ole.uff.br

2 Ressalto que só utilizei textos publicados em revistas especializadas e livros. Não avaliei textos em páginas de opinião ou blogs.

${ }^{3}$ Forma de ER em que os alunos, pais ou representantes legais dos estudantes declaram a sua religião e o curso é dado de acordo com os dogmas da religião declarada. O modelo em contraposição é o interconfessional, que busca discutir todas as religiões quando possível ou, pelo menos, uma ideia de sagrado universal.

${ }^{4}$ Campo é conceito de Pierre Bourdieu e significa um espaço de luta de agentes e de instituições pelo monopólio da violência simbólica legítima no seu interior e pela posse do capital próprio desse campo.

${ }^{5}$ O Projeto Escola sem Partido foi criado pelo Procurador Público do Estado de São Paulo, Miguel Nagib, a pedido da Família Bolsonaro como proposta de reforma nas escolas e universidades brasileiras. O objetivo desse Projeto é combater uma suposta doutrinação ideológica de base marxista nas instituições públicas de ensino. Tal movimento acusa os governos do Partido dos Trabalhadores como difusores dessa doutrinação.

${ }^{6}$ Disponível em: http://www.pge.sp.gov.br/centrodeestudos/revistaspge/revista2/artigo5.htm . Acesso em 25/07/19.

${ }^{7}$ Disponível em: http://www.direito.mppr.mp.br/arquivos/File/relatoriodhesca.pdf . Acesso em 20/07/19.

${ }^{8}$ Disponível em: www.iser.org.br .Acesso em 02/08/19

${ }^{9}$ Disponível em: www.meel.org.br . Acesso em 02/08/19.

${ }^{10}$ Disponível em: https://sxpolitics.org/ptbr . Acesso em 29/07/19.
} 